\title{
MOMENTOS DEL DIBUJO: UN ACERCAMIENTO A LA CONDICIÓN ESCOLAR
}

Héctor Alonso Monsalve Pulido bmonsalve74@botmail.com

Estudiante de la Maestría en

Educación

Universidad Pedagógica y Tecnológica de Colombia (Uptc)

Docente de educación media, Secretaria de Educación de Boyacá

Institución Educativa Técnica Tomas

Vásquez Rodríguez - Paipa (Boyacá).

Docente catedrático Uptc

Grupo de investigación Creación y

pedagogía

Articulo de reflexión

Fecha de receppioin:

17 de septiembre de 2010

Fecha de aprobación:

10 de noviembre de 2010

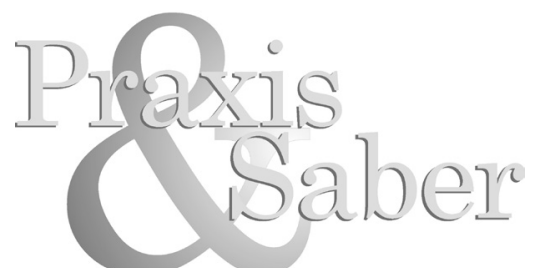

Revista de Investigación y Pedagogía Maestría en Educación. Uptc
MOMENTS OF DRAWING: AN APPROACH TO THE SCHOOL CONTEXT

MOMENTS DU DESSIN: UNE APPROCHE `A LA CONDITION SCOLAIRE

MOMENTOS DO DESENHO: UMA APROXIMAÇÃO À CONDIÇÃO ESCOLAR. 


\title{
Resumen
}

Este trabajo de reflexión parte de la intención de reconstruir el significado del dibujo, para que sea posible su lectura en la condición escolar; se enfatiza en su proceso de realización, denominado momento, que se define como la posición activa del concepto dibujar; esta perspectiva busca una manera de describir el proceso de ejecución de expresiones gráficas, que aparece en la edad escolar, incluyendo los elementos que se involucran durante su ejecución; así se desvirtúa la posición unilateral objetual que se acostumbra a tener con el dibujo infantil. Con la observación, a distancia, mediante relatos como manera de describir los momentos, se presenta una oportunidad para interactuar con los factores y procedimientos de realización de la creación, los cuales serían relevantes para el análisis pedagógico.

Palabras clave: Dibujo, Momento, Pedagogía.

\begin{abstract}
This reflection article aims at reconstructing the meaning of drawing in order to make its reading possible in the school context. The emphasis is placed on the process of achievement called moment, defined as the active position of the concept of drawing. This perspective looks for a way to describe the process of development of graphic expression which appears at the school age, including the elements involved during its development. In this way the unilateral objectual position usually associated with children's drawing is subverted. Through observation from a distance, by means of narrative description of moments, we are able to interact with the factors and procedures that achieve creation, which will be relevant for pedagogical analysis.
\end{abstract}

Key words: Drawing, moment, pedagogy 


\section{Résumé}

Ce travail de réflexion part de l'intention de reconstruire le sens du dessin, pour que sa lecture soit possible dans la condition scolaire; on met l'emphase sur son processus de réalisation, nommé momento, qui est défini comme la position active du concept dessiner; cette perspective cherche une manière de décrire le processus d'exécution des expressions graphiques, qui apparait ‘a l'âge scolaire, y compris les éléments qui se mêlent pendant son exécution ; ainsi, on dévertue la position unilatérale objectivable qu'on a l'habitude d'avoir avec le dessin enfantin. Avec l'observation, ‘a distance, au moyen des petites histoires comme une manière de décrire les momentos, on présente une occasion pour interagir avec les facteurs et les procédures de réalisation de la création, lesquels seraient de relevance pour l'analyse pédagogique.

Mots clés: Dessin, Momento, Pédagogie.

\section{Resumo}

Este trabalho de reflexão parte da intenção de reconstruir o significado do desenho, para que seja possível sua leitura na condição escolar; enfatiza-se em seu processo de realização, chamado momento, o qual se define como a posição ativa do concepto desenhar. Esta perspectiva busca uma maneira de descrever processo de execução de expressões gráficas, que aparecem na idade escolar, incluindo os elementos que se relacionam diante seu execução; assim desvirtua-se a posição unilateral objetual que se acostuma a ter com o desenho infantil. Com a observação, a distancia, mediante relatos, como maneiras de descrever os momentos, apresenta-se uma oportunidade para interatuar com os fatores e procedimentos de realização da criação. Os quais seriam relevantes para o analise pedagógico.

Palavras centrais: Desenho, momento, pedagogia. 


\title{
DEFINICIÓN DE DIBUJO
}

\author{
"Estamos siempre dibujando" (Saul Steinberg)
}

Es difícil precisar un significado general de dibujo, ya que este cambia en su denominación, tanto de intenciones como de nombres, en el tiempo y en los campos del conocimiento. "La historia del dibujo es la historia de sus nombres" (Gómez, 2005, p. 14); cada pensamiento y ejecución se podría considerar como dibujar sobre los múltiples soportes, situaciones y estados espaciales, por ello el dibujo se puede concebir como una probabilidad de habitar la vida humana. En los espacios vivenciales se construyen escenarios donde se generan situaciones, y frente a estas el acto humano define su decisión de obrar y actuar, dibujando una posibilidad de participación con múltiples maneras de interpretación.

En la antigüedad, el dibujo era el soporte para la pintura y la estructura para la escultura; se establecía como un paso anterior a la verdadera obra y se le daba importancia secundaria, que estaba ligada a unas leyes muy establecidas, inscritas en cánones determinados por el estudio de la forma con relación a la intención explícita; en la actualidad, el dibujo es aún un paso para llegar a una intención, pero también es la intención principal de una obra. Nos podemos ubicar hoy con más seguridad, sin necesidad de limitarnos a sustentar el dibujo desde un pensamiento positivista, para destacar con más acentuación el valor del trazo como prolongación de las emociones de quien interviene el soporte; en este sentido, el dibujo también cobra gran importancia desde el gesto de la intervención; la línea toma una autonomía sin necesitar estar respaldada por otras maneras de apoyo plástico adicional.

El valor apreciable del dibujo está en la manera como se configura en cada persona, en cómo logra crear conciencia de sus actos y permite construir nuevas posibilidades que no hacen parte en principio de los intereses locales; puede que cada instante del dibujo en su época se haya encaminado hacia una utilidad cumplida por el dibujo y el arte en su momento; recordemos el legado de Jacob Burekhard, mencionado en el libro El uso de las imágenes, de Gombrich: "el arte como tarea, ese es mi legado" 2003 , p. 34), donde justifica la fuerte relación del desarrollo del arte con la utilidad pedida. Pese a ello, independiente a esa fría intencionalidad que se logra crear en los tiempos de normalidad y pasividad del arte, cada artista hace de su trabajo una construcción 
de caminos que posibilitan transformar un mero oficio en un completo compuesto alquímico, donde se comprometen muchas concepciones y decisiones en un camino, sin reconocerse aún hacia ese oro deseado de la satisfacción. La inquietud hacia la experimentación hace que en el dibujo se construyan nuevos caminos, con la motivación de encontrar una gloria personal, que se convierte como una constante búsqueda en toda la vida del dibujante.

Desde el momento en que el hombre descubre el rastro de su cuerpo, se comienza a configurar el dibujo como la posibilidad humana de interacción, desde las intenciones que se fueron apropiando con el tiempo, y que hoy en día se siguen validando y transformando de acuerdo con la reflexión que se ha tenido de él, y que gracias a la manera como se ha profundizado en las diferentes disciplinas humanas han servido como instrumento para la comprensión del mismo mundo transformado por la mente del hombre.

El dibujo, para muchos, es el resultado de graficar sobre una superficie o materia; tradicionalmente, esta denominación puede ser aceptada como tal, ya que se ha tenido desde muchos siglos atrás esta idea; pero poco se menciona que detrás de este simple resultado hay una serie de apreciaciones y operaciones que empiezan a dar un sentido más completo y permiten tener acercamientos más específicos a la hora de realizar una aproximación o análisis.

Cada manera de dibujar, en su momento, se configura por su ejecución, intención y paradigmas establecidos; "el dibujo no es solo aquello que se determina en la representación, sino en aquello que se puede nombrar de las operaciones que realiza el dibujante" (Gómez, 2005, pp. 25-26).

Se mencionaba al principio que el dibujo ha estado involucrado en todos los campos del conocimiento, y desde cualquier posición que se aborde tendrá una sustentación significativa de su importancia, determinación y trabajo que ha desarrollado desde allí. Los avances técnicos y conceptuales se valen de la pertinencia del dibujo en la actividad humana; esto nos dice que el dibujo no se desliga de la cotidianidad humana y además se convierte en el medio de intercambio de experiencias y desarrollo de estructuras mentales necesarias para vivir y comprender.

Considerando el dibujo como una expresión que antecede al lenguaje oral, está ligado con la intimidad del ser, parte de una libertad individual y construye caminos de experimentación 
donde se hace autorreconocimientos de sí mismo para poder configurar una visión de lo que no ha sido visible aún.

El dibujo, más que un acto de representación de una idea, es un sistema que permite construir, clasificar, ordenar, problematizar, redireccionar una situación, y hace transformaciones de estructuras establecidas, obedeciendo a intenciones íntimas para una nueva significación. Para describir mejor el proceso del dibujo, se puede citar en esta ocasión a un artista que ha permitido destacar la importancia del proceso, mas que la obra, objeto final. Joseph Bueuys es un artista que crea sus propias reglas en sus dibujos, a pesar de seguir órdenes casi matemáticas y clasificaciones que parecieran ser esquematizadas; su propia intención sistematizada se vale de varias estrategias para permitir una fludifiación de unas a formas a otras. "El dibujo para mí existe ya en el pensamiento. Si los significados completos e invisibles del pensamiento no están en una forma, nunca resultará un buen dibujo" (Rabazas, 2000, p. 186).

El dibujo, para Beuys, es un sistema fluido que puede generar sus propias reglas como estrategias para llegar a lo que llama una transustansación, manera activa del proceso que hace posible una consideración de las formas desde cierta intimidad. El dibujo en Beuys es una de las tantas posibilidades de operaciones y caminos que rompen con la diferenciación entre lo racional y emocional, dejando a un lado el objeto final como obra, destacando el valor importante que tiene el proceso en el trabajo y sus transformaciones. El ejemplo en Beuys, desde el orden conceptual, nos permite ratificar la importancia del dibujo en su proceso, más que el mero producto objeto final, y nos alienta a seguir pensándolo como insumo para reflexión y desarrollo pedagógico desde las posiciones que se quiera.

"Dibujamos y nos desdibujamos en la medida que recuperamos o perdemos el hilo conductor que nos produce la idea, en esta maraña de trazos en la que definimos las imágenes. Plan y pérdida se autocomplementan en cada trayectoria de nuestro trazo. Dibujar es establecer una línea de doble memoria, desde la que se organiza la experiencia de nuestro conocimiento" (Gómez, 2005, p. 25); más que el acierto en el dibujo, es la experiencia que se logra, la cual mantiene activa la intención de dibujar y seguir escudriñando en la forma desconocida hasta que se logre llegar a un nuevo estadio que sigue un rumbo, dejando en el camino la adquisición de formas y conocimientos provisionales. 


\section{EL DIBUJO INFANTIL}

Al parecer, fue necesario realizar una separación entre el dibujo infantil y el adulto o profesional para hacer visible la importancia de la expresión gráfica infantil, aunque con el tiempo la línea limítrofe se haya borrado desde el mismo arte y los artistas.

Para el niño el dibujo es una manera vital de relacionarse con el mundo, conocerlo, experimentarlo y sentir con el tacto toda acción que lo une con el exterior; el tocar el espacio; hasta en el vacío el dibujar se convierte en la conexión e irrupción del ser con el universo; "el bastón del niño para conocer el mundo”, en Rousseau (citado en Gómez, 2006, p. 306).

La experiencia de tomar objetos que producen líneas, e intervenir superficies es una exploración que se torna más importante que el mismo producto final. La acción corporal que el producto gráfico hace nos permite ampliar mucho más la idea reducida del dibujo; se comienzan a involucrar todas la posibilidades que el cuerpo puede hacer en el mundo, como parte del dibujar dancístico, con ritmo casual y rutinario, se puede considerar ahora como vivencial, propio de cada uno, es huella personal y, en principio, no es relevante una influencia de cánones globales u otros. Es necesario que se mantenga la originalidad en cada manifestación dibujada, ya que estarían cargados de actos creativos, que trascienden del mero ejercicio gráfico a un estilo original de pulsación y vida; pueden ser interpretaciones que desbordan la mera copia representativa formal, para que indague en varias posibilidades de actos con un cierto misticismo, para que no permita que se alimente con el tiempo el miedo o pavor en la edad adulta a dibujar, como se ha percibido.

No ha sido ajena a la teoría pedagógica la idea de querer justificar la importancia del dibujo y la expresión artística como algo más que un proceso sensitivo y emocional, de allí la necesidad de demostrar que dibujar es un complemento que involucra la cognición y ayuda a la producción de conocimiento y al desarrollo de estructuras mentales, para la solución y desenvolvimientos de problemas reales. Esto permite, en principio, darle un estatus favorable al dibujo, pero, pese a que ha sido tan utilizado por todas las ramas del conocimiento, se ha condenado en sí mismo a volverse invisible en su importancia. 
Los análisis que se han hecho del dibujo confrontan situaciones teóricas que han involucrado su problemática en el uso y la intención de la formación escolar. Por semejanza con la manera como se ha reflexionado pedagógicamente en nuestro medio, en el dibujo y la creación artística, desde la visión sajona, podemos apreciar una necesidad básica de tener una posición antagónica entre arte y ciencia: "la visión positivista del arte, aquella que dio origen a una observación de la naturaleza independiente de los propósitos humanos" (Efland, 2004, p. 246). Esta es una posición que reduce el arte a la mera reproducción natural e impide que se conciba como posibilidad de análisis, que solo podría permitirse en el desarrollo científico; esto nos ha dado a conocer una confrontación acerca de las diferentes apreciaciones del estudio de la expresión gestográfica, "las etapas del desarrollo, teorías cognitivas del desarrollo, educación progresista, metáfora biológica" (Efland, 2004, p. 245), como un afán por la clasificación que ha ubicado el arte en una condición meramente emocional, alejado de un proceso de cognición y desarrollo mental; son clasificaciones que excluyen muchos aspectos de la formación intelectual y tratan de ver la práctica artística como actos desbordados de espontaneidad que tan solo se podían considerar desde el psicoanálisis, y se queda corto con la idea de relacionarlo con procesos mentales y de construcción de conocimiento.

Pero el fin de darle importancia desde el proceso cognitivo al arte, y más precisamente al dibujo, ha permitido conocer no solo esa gran integralidad que refieren algunos teóricos del desarrollo (al menos en principio), sino el papel tan importante que puede llegar tener esa práctica en la comprensión y el análisis del saber; además que, como menciona precisamente Lowenfeld, "la expresión gráfica del niño es el resultado de la mente" (1961, p. 7), lo que demuestra un proceso mental que se convierte en conocimiento y transformación del pensamiento, a la par que involucra la capacidad de tomar decisiones, incluir aspectos culturales, afianzar actos creativos y hacer todo un proceso complejo que desborda la mera lectura clasificatoria que comúnmente se hace con la observación de los trabajos infantiles.

Darles importancia a los niños y diferenciar su condición de la de los adultos en la práctica del dibujo no ha alcanzado los doscientos años; superar de la idea de considerar al niño "como un adulto en miniatura" que piensa igual, sin importar la edad, y que puede tener un mismo sistema de enseñanza sin ningún problema, pensar que "el niño es un recipiente vacío" (Rousseau, citado por Gómez, 2006, p. 306) que se debe llenar poco a poco del conocimiento que aporta 
la educación, fueron apreciaciones que mostraron la necesidad de incluir la concepción infantil como componente básico para la enseñaza y la motivación de procesos significativos.

Trazar un recorrido, un tanto superficial, que defina algunos aspectos sobresalientes de la enseñanza del dibujo a través de la historia obliga a tomar posiciones que bien podrían servir como precedente en cualquier tiempo, como lo es pensar el dibujo desde una forma mística, de sentir que esa práctica nos beneficia en algo; vale la pena citar en esta ocasión la frase que Gombrich menciona con relación a los garabatos: "las fantasías y pensamientos ocultos en los garabatos son aquellos de los que el garabateador quiere liberarse" (Gombrich, 2003, p. 6), que bien podría definir la práctica en los rituales gráficos que se hacían en las cavernas el hombre primitivo, como el niño que dibuja mientras soporta una clase de ciencias.

De otra forma, y de manera riesgosamente general, podemos mencionar cómo ha sido considerada la práctica o la enseñanza del dibujo a través del tiempo. Desde el pasado, las culturas clásicas ya definían el dibujo como una materia escolar; ellas, que desde el cuerpo y su representación definían unos cánones de construcción idealizada en busca de lo bello, determinaban esta situación de representación gráfica como algo alejado de una realidad física y que carecía de importancia por ser reproducción de una idea; "para Platón, el proceso artístico significaba copiar algo que poseía una existencia anterior y se quedaba corta en su aspiración a la verdad total" (citado en Efland, 2002, p. 36); aunque considerado el dibujo como algo menor, fue necesaria su práctica, que se fue convirtiendo en la base de expresión plástica y ocupó una posición sobresaliente y necesaria para la actividad artística, transformándose en la vena principal de los procesos académicos posteriores. Durante la Edad Media, al carecer de un sistema escolar, la práctica del dibujo se trasladó a los talleres de artistas al servicio de los intereses de turno, siguiendo íconos establecidos en la producción artística; la imagen ayudó en la ilustración de la fe, y aunque en principio se advertía en el cuidado de caer en la adoración de la imagen, posteriormente se suprimió por orden del Concilio de Nicea (787 d.C.) para afirmar que "la adoración que presentan los creyentes a las imágenes se transmite al sujeto representado en ellas" (De Beardsley, citado en Efland, 2002, p. 43); situación que permitió ubicar las artes en uno de los puestos más importantes en oficio de la fe y la evangelización. Desde el Renacimiento, la idea de separar las bellas artes de la artesanía logró darle un estatus más favorable al arte, como un acto privilegiado que mantenía algo más 
sublime que su elaboración y su uso; posteriormente, en el siglo XVIII, aunque con un proceso escolar no definido, aparecen las escuelas de dibujo como formación desde temprana edad para el adiestramiento de la imitación de la naturaleza en busca de lo que pudiera llamarse la belleza, influenciada en algo por las culturas clásicas, manteniendo presente la dicotomía platónica y aristotélica del arte como creación y copia.

En este orden no podemos dejar de mencionar a Comenio, que ya desde el siglo XVII había tomado el dibujo como una ayuda para la enseñanza; él había permitido incluir el dibujo como una de las maneras de indagación de la comprensión del mundo y las ideas, en sus estrategias, y consideró el dibujo como una herramienta eficiente para cumplir diferentes objetivos. Para Comenio, la consideración del dibujo en la enseñanza fue una posibilidad instrumental que permitía que se desarrollaran exploraciones hacia una didáctica formativa.

El siglo XIX es decisivo en el proceso de formación escolar, por dos razones: la primera, porque se estructura un sistema educativo, y dentro de este se acoge el dibujo como materia; el dibujo se divide en técnico y artístico; y la segunda, porque se descubre y da importancia a la manifestaciones de los niños. Solo a partir de la mitad del siglo xIx se le da importancia al arte del niño, con lo que aparece el arte infantil, y se deja a un lado la equivocada idea de ver los dibujos infantiles como errores que se debían corregir: "la manera propia de dibujar los niños y las niñas son garabatos, desproporciones, esquemas característicos, esto dejó de interpretarse como un cúmulo de errores o deficiencias que habían que corregirse, y pasó a ser considerada como la manifestación genuina y propia que tiene la infancia de comprender el mundo" (Gombrich, 2003 p. 222)

Algunos artistas interesados por el grafismo infantil comenzaron a realizar investigaciones con el fin de darle ese valor espontáneo que se dejaba entrever; es el caso de Franz Cizec (1865-1946), quien vinculado como expresionista se dejó llevar por las características de dichos grafismos para pretender considerarlos como estilos artísticos y apoyarlos, abriendo escuelas de arte infantil para seguirlos cultivando desde temprana edad.

Una mirada hacia el dibujo infantil centra la idea de querer realizar un análisis más atento a las diferentes manifestaciones que el niño hace y cómo se relacionan directamente con el entorno y su entendimiento. Campos del conocimiento como la psicología y la sociología se apropian 
del campo pedagógico, logrando presentar varios estudios evolutivos del dibujo infantil, para lo cual se dan a conocer varios autores que hacen clasificaciones de las manifestaciones gráficas, relacionándolas con la edad y etapas que se desarrollan normalmente; autores como James Sully (1885), Herman Luckens (1896), George Kerchenteiner (1905), C. Burt (1921), Henry Luquet (1927) y Víctor Lowenfeld, entre otros (Marín, 2003, p. 28). Todos estos estudios de clasificación, que se determinaban de acuerdo con aspectos relacionados con el gesto, la influencia del realismo y otras influencias sociales, se convierten en bases para la determinación de varios esquemas pedagógicos, como ejes de referencia para las etapas de desarrollo evolutivo; situación que en su principio se convertía en una muy aceptable manera de ver el desarrollo, pero a causa de una interpretación instructiva en la practica pedagógica, que se le dio a esas descripciones dadas en cada etapa, se tomaron como pasos por seguir, delimitando de forma muy radical cómo y qué debía dibujar el niño de acuerdo con su edad.

A mediados del siglo xx se tenían las etapas del desarrollo como eje referencial, como maneras de esclarecer algunos aspectos de cómo aprende el niño y qué elementos sobresalientes iba adquiriendo de acuerdo con su edad y etapas establecidas. Estas determinaciones bien podrían considerarse un buen referente para la construcción de nuevas teorías que en principio se atrevieran a abordar estos temas de investigación social con algunas dependencias paradigmáticas.

Progresivamente, para abordar la preocupación por el dibujo en la edad infantil, se continuaba insistiendo en determinar momentos evolutivos, no solo desde aspectos de forma y adiestramiento, sino incluyendo elementos que influenciaban al niño en su medio. Así, las fases o periodos se convertirían en determinaciones más generales que demostraban cómo el niño, dentro una formación escolar normal, iba adquiriendo la aceptación por esquemas y juicios construidos por la experiencia social. W. Ives y Howard Gardner (2005) presentaron una clasificación ampliada, donde determinaron las influencias culturales en los dibujos infantiles en estas etapas: dominio de patrones universales, florecimiento del dibujo y apogeo de las influencias culturales (Gómez 2005, p. 25); estas determinaciones no describen una especificación rígida, más bien dan una visión amplia acerca de cómo el niño se va desenvolviendo y va convirtiendo el dibujo en un elemento de experiencia y comunicación con su medio, apropiándose de elementos que le proporciona su entorno cultural. 
El dibujo infantil es un tema que necesita acercamientos que no se queden anclados en las intenciones positivistas, sino que permitan considerarlo un acto social que facilita entender el valor personal que cada niño le da en sus primeros años de vida y en el camino que está comenzando a realizar con la libertad que se merece.

\section{APROXIMACIÓN INVESTIGATIVA AL DIBUJO ESCOLAR}

Uno de los problemas que se mencionan en El arte como experiencia, de Dewey, es el reaccionado con el análisis y el desarrollo del arte distanciado de la situación localizada de la obra: "los objetos artísticos se separan tanto de las condiciones que los originan como de su operación en la experiencia" (Dewey, 1963, p. 10), ocasionando una aplicación alejada, separada de la propia realidad de ejecución; al alejarse los juicios de valor del espacio en que se ha desarrollado la obra de arte, se vuelve esta apreciación superficial e impertinente, desviando los posibles valores que este ha ejercido. En la formación artística se han evidenciado esos rompimientos en la apreciación dentro del sistema escolar, donde las manifestaciones artísticas se han convertido tan solo como procesos demostrativos de una práctica instructiva, alejada del valor procesual que permitiría indagar en la experiencia vivida y significante.

El interés desde el dibujo ha estado centrado en ubicarse en una posición cercana a los procesos logrados en la práctica, donde se puede desligar de la mera lectura denotativa de las formas graficadas, para centrarse en la experiencia que tiene el estudiante en los estados de construcción de procesos dirigidos, con miras a la maduración de formas de proceder y complementación de estilos creativos. Aunque en esta situación la experiencia que se acomoda no es la del arte, empieza por ser aquella que, en los términos de Dewey, "es una experiencia débil e incompleta" (p. 11), ya que no se ubica en una dirección madura, completa y unificada para una intención artística, pero sí es un inicio para poder describir las situaciones y pensar en el desarrollo de maneras del dibujo como una posibilidad de apreciación de estilos y formas de aprendizaje, y, por qué no, el inicio a la conformación de procesos conscientes de la propia vida, hacia un objetivo, que es la que enuncia Dewey, "una intención unificada en torno a un objeto construyendo una unidad singular" (p. 11). 
El dibujo, como un acto humano, se desarrolla como tal; con la realización de procedimientos se aprende y se transforma, siempre con una posición de búsqueda, que es lo que hace que se vea como más que una habilidad; en este sentido se han realizado conexiones de términos que han mostrado un camino para la apreciación del dibujo en los estudiantes durante la experiencia y los procedimientos que se realizan, que son caminos que se han construido con la reflexión de ellos mismos. Estas relaciones son:

\section{El dibujo y la palabra}

Con la intención de hacer del acercamiento al dibujo un acto dialógico, la relación dibujo-palabra proporciona un paso para el complemento del acto y la reflexión de este como una de las formas más completas de la actividad humana.

Muchos autores coinciden en darle el papel principal al dibujo frente a los demás medios artísticos, porque desde ahí se pueden intercambiar opiniones del proceso que se ha realizado para llegar a la obra, y dentro de esta denominación, la palabra se convierte en la manera más viva que trasciende al entendimiento en algunos aspectos de la obra, que tal vez en principio era solo personal. La palabra, desde el campo pedagógico, involucra posiciones importantes del dibujo, por su forma, condiciones, circunstancias; esta relación permite ampliar el papel que se puede tener dentro de la vida humana, afirmando que el dibujo, en los espacios escolares, muchas veces llega a ocupar un papel tan importante como la escritura, ya que, además, es considerado un medio comunicativo que viene cargado de gran significación por donde se le pueda abordar.

Siendo el dibujo, entonces, una posibilidad de reflexión que se involucra en el campo pedagógico, la palabra funciona como un insumo pertinente que complementa la práctica, pero no en cualquier momento ni de cualquier forma, ya que hay momentos del dibujo en el que no necesita ni es pertinente la palabra para su complemento; es adecuado siempre y cuando no extinga la posibilidad de interpretaciones sin límites en el momento de realización.

El niño y el joven pueden ser influenciados cuando se les habla de lo que están haciendo; al respecto se puede citar uno de los cuentos infantiles más reconocidos, El Principito (De Saint-Exupéry, 2003), el cual menciona la desmotivación que tuvo el personaje cuando realizó 
un dibujo, y al mostrárselo a los adultos no solo no lo entendieron, sino que exigían una explicación para poder comprenderlo; la situación en el cuento se presenta como justificación del porqué el Principito dejó su carrera de artista y se dedicó a otras cosas.

La interferencia de la palabra en el dibujo de los niños debe ser tan sutil que no afecte susceptibilidades, ya que el comentario adulto resulta en muchas ocasiones determinante para encaminar la labor. Esto no significa que sea impertinente hablar del dibujo, sino que se ha de hacer manteniendo cierta distancia, de tal manera que no interfiera en la posición ganada por los niños con sus propios hallazgos.

Hay momentos en los que el dibujo es una experimentación individual, y sobran las palabras, como es el caso de los primeros garabatos que logra el niño en sus primeros años; en ellos, tal vez, ni la comunicación ni la influencia de la imagen toman importancia, su realización es todavía un acto interiorizado de aprehensión y comprensión del mundo tangible, del movimiento, de su cuerpo y la relación con los materiales; no existe aún la necesidad de una explicación o una reflexión de lo que está realizando, tan solo se vuelve importante la experiencia y la vivencia de la situación.

Pero Gómez Molina menciona que una vez dicha por el niño la palabra que define el dibujo, comienza a tomar un papel importante la relación imagen, palabra y trazo o dibujo (Gómez, 2005 , p. 26); en esta posición, ya sea por condición o por necesidad del mismo niño de utilizar la palabra, es cuando se ve el principio de una situación en que la palabra se presenta en el dibujo como pertinente e impertinente, por varias razones:

La palabra en el dibujo no es una explicación del dibujo ni una definición específica de él, es decir, la palabra no es la explicación del proceso; la palabra permite construir el campo hacia la creación, alejada de explicar el por qué de su realización, "es el elemento clave que abre el horizonte de la imaginación" (Gómez, 2005, p. 25-26), es una manera de complemento mas que una mera intención explicativa o para descifrar.

La forma de involucrar la palabra obedece a un sentido táctil, donde se espera que su participación no pase más allá del acompañamiento y la construcción de actos dialógicos. La inclusión de la palabra en la práctica del dibujo se presenta como una ayuda para la fluidez, que permite trascender 
el mero oficio representativo; Gómez cita, al hablar del dibujo contemporáneo, a Calvino, cuando aprecia las formas de narración en Ciudades invisibles, que aparecen como una posibilidad de presentar un dibujo con palabras, al emperador acerca de sus territorios desconocidos: "las estructuras del lenguaje establecen sucesivos andamiajes de la representación y cómo su narración se ve alterada en la manera que sus nombres posibilitan" (citado en Gómez, 2005, p. 26). Gómez deduce una fuerte relación entre el nuevo dibujo contemporáneo y el lenguaje

\section{El momento como proceso}

Considerar el dibujo como momento deja a un lado la posición común de esta práctica, como determinante por su producto, y abre una posibilidad de incluir los muchos elementos que comprometen su acción, dándole una importancia merecedora más al proceso realizado que al resultado final. Dentro del mismo concepto contemporáneo en el trabajo artístico, definido desde el oficio curatorial, se mantiene la idea de describir los recorridos hechos por el artista para llegar a su obra; esta apreciación nos lleva a la idea de ir junto con la palabra a la descripción, que además de darnos a conocer lo que sucede cuando se dibuja, permite que se siga construyendo el camino a otras posibilidades siempre vivas de la práctica del dibujo.

Una de las apreciaciones obtenidas de la aproximación de las prácticas del dibujo en la institución fue el momento que hacía posible su ejecución, mediante los relatos realizados con la observación de factores y detalles que iban apareciendo; esto acercó a la idea de querer llegar a la aproximación complementaria que el dibujo causa en estos espacios de intercambio sensitivo.

Más que realizar una clasificación rígida y determinante de las diferentes manifestaciones que se pueden encontrar a través de la observación de los instantes, es esencial encontrar algunas asociaciones y aspectos insistentes en los momentos que se permite hacer lectura de las acciones que motivan el dibujo dentro de esta institución educativa, se pueden mencionar tres momentos que parecían imperantes y motivadores en la aparición del dibujo en los estudiantes, aunque no definitivos, ya que cualquier dibujo pudiera estar pisando los tres momentos en un mismo instante. Estos momentos no son diferenciados en los mismos instantes, sino que son estados interactivos que bien podrían encontrarse en alguna situación compartiendo varios 
momentos o simplemente separados. Los momentos nombrados son: la experimentación, la identidad y la expresión.

El dibujo, desde el momento de la experimentación, es un acercamiento a la posibilidad del aprendizaje autónomo y dirigido del dibujar desde el oficio; esta condición permite incluir en la descripción los procesos en que ha sido posible el dibujo en el espacio escolar, que va desde el adiestramiento tradicional hasta la condición libre que logra el niño y el joven; esto lo ha involucrado como proceso de apropiación, como dirección intencional, como posibilidad liberadora de existir en las circunstancias físicas.

El momento experimental es ese instante del dibujo que permite emprender un camino a su apropiación desde directrices probables para su enseñanza en la mediación de lo integral humano, encontramos practicas tan esquemáticas como la copia, y tan deliberadas como las que se practican desde el ocio; la experimentación es una constante que permite indagar sobre materiales, circunstancias, asociaciones, son instante que se encuentran en la incertidumbre con la motivación de descubrir siempre algo nuevo. La experimentación es una manera significativa de construir conocimiento.

En el momento de la identidad, el dibujo involucra la propia acción en la búsqueda personal; es una posición instrumentalista, en el buen sentido, en que el estudiante ha utilizado el dibujo como la brújula para la comprensión y el posicionamiento de estados sociales en la incertidumbre juvenil; desde esta posibilidad se presenta el dibujo como una práctica intencional e interesada, que deja ver una gran parte del desarrollo de la personalidad y la decisión.

La expresión, como el último momento propuesto, involucra el dibujo como hilo de conexión social; el sentido instrumental hace posible la construcción de canales expresivos que han sido activados por la necesidad de trasmisión de información más simbólica que inmediata, recibiendo una interacción que evidencia una necesidad reservada entre tribus y otros órdenes sociales de agrupaciones establecidas.

El dibujo como momento es una oportunidad de lectura dentro del espacio escolar; con las la múltiples vivencias que se desarrolla en la cotidianidad, la narrativa que materializa la relación dibujo-palabra vuelve más amplia la perspectiva que se tiene del concepto dibujo, como algo más que un mero producto realizado con cierto adiestramiento. 


\section{CONCLUSIONES}

$\mathrm{Al}$ realizar una separación tajante entre el dibujo infantil y el adulto o profesional, el primero se pudo apreciar como una creación libre y accesible a ser tema de estudio; posteriormente, los mismos artistas fueron borrando esa línea de división para compartir la complejidad que cada manifestación lleva. El dibujo nos enseña un camino reflexivo que toma importancia en la práctica, más que en su producto final. Los procedimientos y operaciones que se efectúan en el momento de dibujar son decisiones que se construyen con el tiempo y la experiencia de la realización de posibilidades concurrentes.

La decisión de nombrar la práctica del dibujo en el espacio escolar desde el concepto de momento nos permitió preocuparnos por la especificación del tiempo y el escenario, y centrarnos en la descripción localizada de la práctica. Los momentos del dibujo son apreciaciones asociativas que se han hecho a partir de la práctica del dibujo en el espacio escolar. Mediante la observación de casos específicos se han podido tejer algunas relaciones que comprometen de manera directa similitudes; estas asociaciones permitieron encontrar estados temporales en su espacio, que se presentan de manera concurrente, dando la posibilidad de abordar el dibujo no como una descripción mera del producto compositivo, forma o intención, sino mas bien desde la posibilidad de encontrar las ocasiones que rodean la práctica dentro de la cotidianidad escolar, las cuales se vuelven propias del espacio.

Uno de los aspectos que se pueden destacar con la experiencia de este ejercicio investigativo es la ruta metodológica que se trazó tras haber experimentado diferentes posibilidades de acercamiento; esta situación dejó ver el problema de la especificidad frente a manifestaciones diferentes, a pesar de tener una similitud en las imágenes y temas. La reflexión que produjeron los procesos de agrupación y selección de la información nos obligó a pensar en otra manera de abordar la práctica, que al final se basó en la acción, más que en el producto mismo.

Pueden haber tantos momentos del dibujo como las particulares creaciones gráficas; se escogieron tres que, según el proceso de observación, se detectaron con un sentido prioritario, ya que involucran tres espacios propios del ambiente escolar, ellos son: 
La exploración, que se involucra en el proceso de enseñanza y aprendizaje, ya que la búsqueda es una motivación que tiene el estudiante para apropiarse de esta práctica, en la cual se aprecia de forma dirigida y del mismo modo autónoma; es muy importante en la práctica del dibujo la provisionalidad en lo que se está haciendo, es decir, la constante indagación permite la creación y la apropiación de estilos para realizar formas dibujadas.

La identidad, que es un momento en el que el estudiante busca el reflejo de su deseo en la construcción de un proceso de pensamiento personal; de ahí que el compromiso con la práctica del dibujo se convierte en parte de la selección de sus gustos, en parte de sus hallazgos y de la comprensión del entorno desde su posición individual y social.

La expresión, determinada aquí como el acto de dejar sacar, mediante maneras plásticas, lo que cada uno tiene dentro y compartirlo con los demás como acto social; se presenta como una forma de interacción que intenta ser una acción comunicativa en el ambiente, con un sentido muy propio entre los jóvenes, buscando unos códigos construidos por ellos mismos como apropiación de esa vía comunicativa, que comúnmente goza de la incomprensión de los docentes y adultos.

Los momentos ocasionales que se han definido son puntos de encuentro que se permiten entrecruzar entre ellos; estos puntos de cruce son puntos de interpretación que tomamos como referentes para la posibilidad del acercamiento investigativo.

La narrativa producto de la posible relación dibujo-palabra nos permitió construir un acercamiento a la descripción analítica del momento que propiciaba el dibujo dentro de la experiencia del espacio escolar.

\section{REFERENCIAS}

Efland, A. (2002). Una bistoria de la educación del arte. Barcelona: Paidós.

Efland, A. (2003). La educación en el arte posmoderno. Buenos Aires: Paidós.

Efland, A. (2004). Arte y cognición. Barcelona: Octaedro. 
Dewey, Y. (1963). El arte como experiencia. México: Fondo de Cultura Económica.

Freedman, K. (2006). Enseñar la cultura visual. Currículo, estética y la vida social del arte. Barcelona: Octaedro.

Gombrich. E. (2003). El uso de las imágenes. Barcelona: Debate.

Gómez, J. (2005). Los nombres del dibujo. Madrid: Cátedra.

GómEz, J. (2006). Estrategia del dibujo en el arte contemporáneo. Madrid: Cátedra.

Ives, W. y Gardner, H. (2005). Arte, mente y cerebro. Barcelona: Paidós Ibérica.

Lowenfeld, V. (1961). Desarrollo de la capacidad creadora. Buenos Aires: Kapelusz.

Marín, R. (2003). Didáctica de la educación artística. Madrid: Pearson Educación.

Rabazas, A. (2000). "Del dibujo de objetos al dibujo como objeto. El modelo de Beuys". Revista Arte, Individuo y Sociedad, 12: 185-227. 
